\section{Estimation of control rod worth in a VVER-1000 reactor using DRAGON4 and DONJON4}

Farahnaz Saadatian-derakhshandeh,

Omid Safarzadeh, Amir Saiid Shirani

\begin{abstract}
One of the main issues in safety and control systems design of power and research reactors is to prevent accidents or reduce the imposed hazard. Control rod worth plays an important role in safety and control of reactors. In this paper, we developed a justifiable approach called D4D4 to estimate the control rod worth of a VVER-1000 reactor that enables to perform the best estimate analysis and reduce the conservatism that utilize DRAGON4 and DONJON4. The results are compared with WIMS-D4/CITATION to show the effectiveness and superiority of the developed package in predicting reactivity worth of the rod and also other reactor physics parameters of the VVER-1000 reactor. The results of this study are in good agreement with the plant's FSAR.
\end{abstract}

Key words: control rod worth • DRAGON4 • DONJON4 • VVER-1000 reactor

F. Saadatian-derakhshandeh, O. Safarzadeh ${ }^{\bowtie}$,

A. Saiid Shirani

Engineering Department,

Shahid Beheshti University,

P. O. Box: 1983963113, Tehran, Iran,

Tel.: +98 212243 1596, Fax: +98 212990 2546,

E-mail: o_safarzadeh@sbu.ac.ir

Received: 30 October 2013

Accepted: 17 April 2014

\section{Introduction}

The determination of the control rod worth is essential to assure safe and reliable operation of the reactor system. Numbers of approaches have been reported in the literature for the calculation of the control rod worth. To measure and validate the worth of control rod in zero power physics test in a pressurized water reactor, the dynamic approach had been reported [1]. They used inverse point kinetics equation to determine the control rod worth from the measured ex-core detector signals. Shimazu [2] developed a method to measure the reactivity of the control rod. Kalcheva and Koonen [3] used a stochastic method to predict the control rod worth of a research reactor. Both deterministic and stochastic methods have been applied to estimate the integral and differential worth of two control rods of the Greek Research Reactor [4]. They used TRIPOLI, a Monte Carlo program [5], to simulate particle behavior in three dimensions. More specifically, for the deterministic approach, NITAWL is used to perform problem-dependent resonance shielding [6], XSDRNPM is applied to obtain cell averaged group constants [7] based on discrete-ordinates method in one-dimensional and $B_{n}$ theory in infinite media, and CITATION has been utilized to calculate flux and multiplication factor by solving the diffusion equation for the whole core [8]. The control rod worth of the research reactor during the fuel burnup is calculated using 


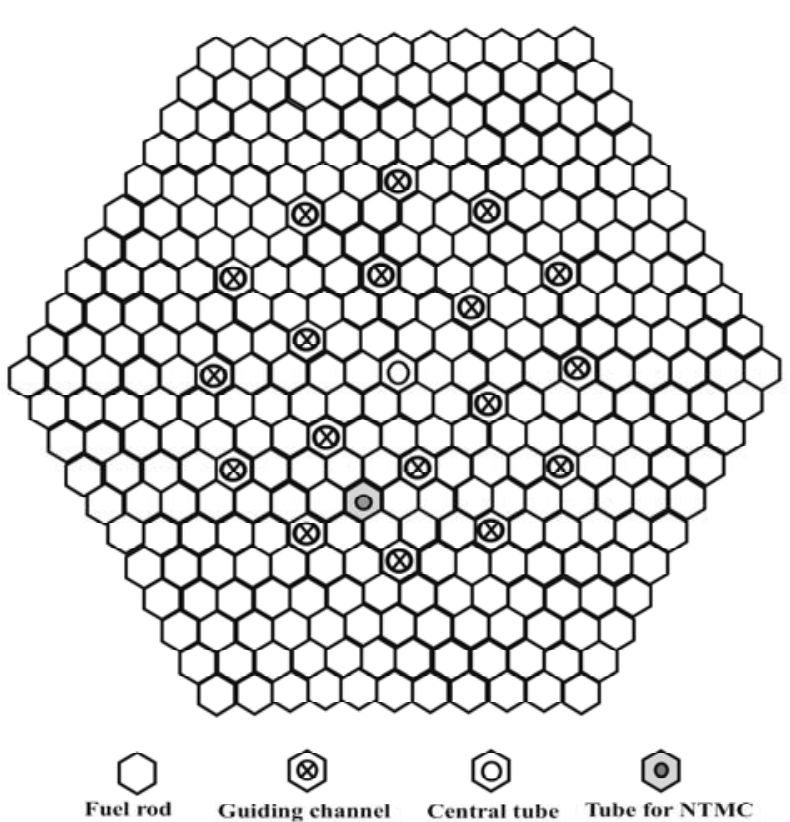

Fig. 1. VVER-1000 Fuel assembly model.

NITAWL/XSDRNPM/CITATION and TRIPOLI [9]. WIMS-D4 and CITATION were employed to calculate the control rod worth of a VVER-1000 reactor [10]. In that study, fuel assembly has been simulated by WIMS-D4 that solves transport equation in two dimensions $(r, \theta)$ by collision probability method [11], and the reactor core was simulated by CITATION.

The best estimate analysis should be performed to reduce conservatism in order to diminish over-design capacity of equipment in the plant, to get more realistic and accurate results, and to establish a wider range of acceptance criteria $[12,13]$. In this paper, we developed a justifiable approach to acceptably estimate the control rod worth of a VVER-1000 reactor. The developed package couples DRAGON4 and DONJON4, and calculate the differential and integral worth of the rod and critical boric acid concentration. DRAGON4 is a lattice code developed to solve Boltzmann transport equation in two and three dimensions, to apply self-shielding effects, and to compute few-group macroscopic cross sections and diffusion coefficients [14, 15]. DONJON4 is a multi-group diffusion solver $[16,17]$.

The remainder of the paper is organized as follows: the next section presents an overview of the considered reactor. In section "Methodology", simulation of the VVER-1000 reactor core and the calculation procedure of the control rod worth are considered. Section "Results" contains the results to demonstrate the capability

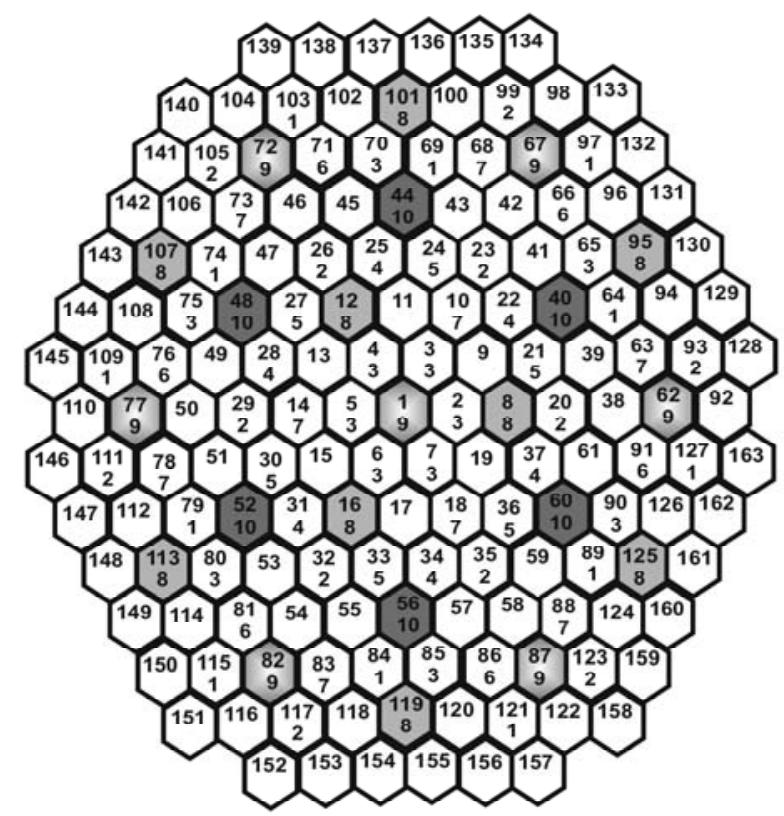

Fig. 2. Control rod groups locations in VVER-1000 core.

of the method. Finally, conclusion and remarks are given in the last section.

\section{Description of the reactor}

VVER-1000 reactor is a pressurized water moderated reactor that has 163 hexagonal fuel assemblies. Each fuel assembly includes 311 fuel rods, 18 guide channels, one central tube, and one tube for instrumentation. The control and the burnable absorber rods have been placed in the guiding channels. The control rod consists of two different materials that are made up of $\mathrm{Dy}_{2} \mathrm{O}_{3} \mathrm{TiO}_{2}$ by $10 \%$ of its length and remaining $90 \%$ consist of $\mathrm{B}_{4} \mathrm{C}$. The model of fuel assembly is shown in Fig. 1. Table 1 describes the six different types of fuel assemblies. To control and maintain the safety of the reactor, ten control rod groups are employed. The locations of the control rod groups in the reactor core are shown in Fig. 2.

\section{Methodology}

The effect of an individual control rod and groups of such rods on reactivity can be determined in two ways: the integral and differential rod worth. The integral rod worth is the total reactivity change due to movement of the control rod to the reactor core. But, the differential

Table 1. Description of fuel assemblies

\begin{tabular}{|c|c|c|c|c|}
\hline \multirow{2}{*}{$\begin{array}{l}\text { Fuel assembly } \\
\text { type }\end{array}$} & \multirow{2}{*}{$\begin{array}{c}\text { Average enrichment } \\
(\%)\end{array}$} & \multicolumn{2}{|c|}{ Number of fuel rods (enrichment, \%) } & \multirow{2}{*}{$\begin{array}{l}\text { Number of burnable } \\
\text { rods (boron content } \\
\left.\mathrm{g} / \mathrm{cm}^{3}\right)\end{array}$} \\
\hline & & Fuel rod type 1 & Fuel rod type 2 & \\
\hline$\overline{16}$ & 1.60 & $311(1.6)$ & - & - \\
\hline 24 & 2.40 & $311(2.4)$ & - & - \\
\hline 36 & 3.62 & $245(3.7)$ & $66(3.3)$ & - \\
\hline 24B20 & 2.40 & $311(2.4)$ & - & $18(0.020)$ \\
\hline 24B36 & 2.40 & $311(2.4)$ & - & $18(0.036)$ \\
\hline $36 \mathrm{~B} 36$ & 3.62 & $245(3.7)$ & $66(3.3)$ & $18(0.036)$ \\
\hline
\end{tabular}


rod worth is the reactivity change per unit movement of the control rod into the core.

\section{Reactor simulation}

To perform the calculation, it is necessary to obtain group constants of the fuel assemblies and reflectors. DRAGON4 has been used to simulate the fuel assemblies in exact details (e.g., see Fig. 1). This computer program contains a collection of models that can simulate the behavior of a fuel assembly, such as interpolation of microscopic cross sections, resonance self-shielding calculation, different solvers for the Boltzmann transport equation with ability to take into account leakage effects, and calculation of condensed and homogenized parameters [14]. In this paper, the SYBILT module is used to solve the integral transport equation using the collision probability method, the SHI module is utilized to perform self-shielding calculations using the generalized Stamm'ler method, and the CPO module is chosen to produce equivalent fuel assembly parameters in consistent format that can be used in forgoing calculation.

In next step, these data are used by DONJON4 to simulate the reactor core. DONJON4 is used to solve the diffusion equation [17]. Figure 3 shows full core modeling of the core with reflectors located around the fuel assemblies. The TRIVAT module is used to perform a three-dimensional simulation by Thomas-Raviart-Schneider method, the CRE module is chosen to recover the group constants of fuel assembly calculated by DRAGON4, and the FLUD module is to compute multiplication factor.

\section{Procedure}

After simulation of the fuel assemblies and the reactor core by DRAGON4 and DONJON4, the control rod worth and the critical boric acid concentration are cal-
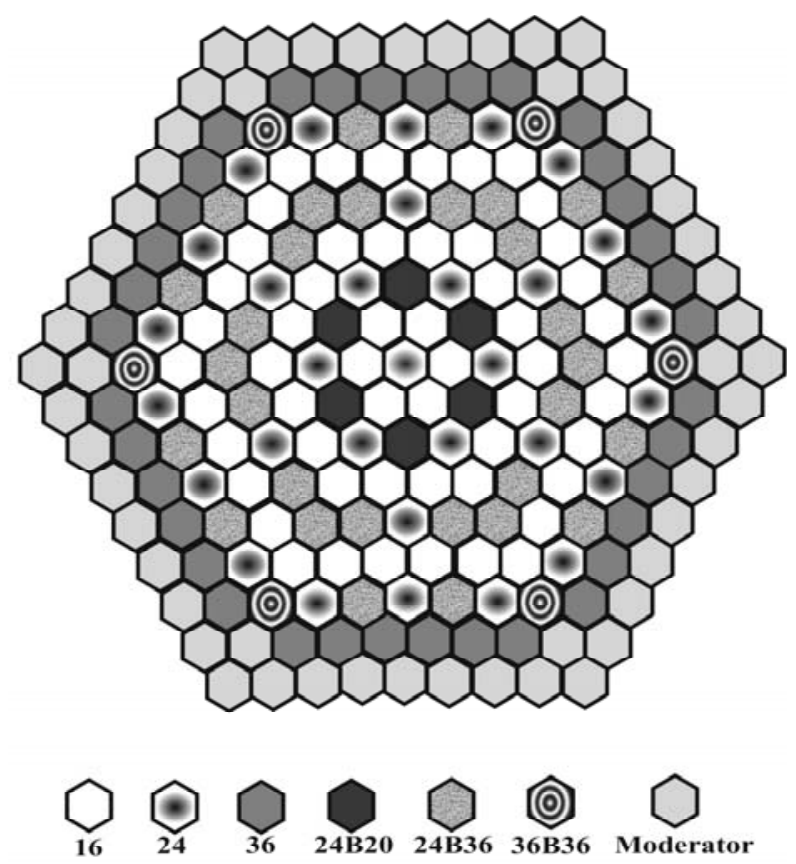

Fig. 3. VVER-1000 reactor core modeling in DONJON4. culated. An auxiliary computer program is developed to couple the codes and calculate these parameters.

A partial length of the considered control rod is inserted into the core from top to bottom and reactivity change is calculated. After inserting each part of the control rod, the critical boric acid concentration is computed for forgoing control rod movement. This approach is repeated till the control rod is fully inserted to the core.

The integral and differential worth of the control rod are obtained by the reactivity change due to the insertion of a partial length of the control rod into the core respectively:

$$
\begin{aligned}
& \Delta \rho_{i}=\sum_{j=1}^{i} \frac{k_{j}-k_{j-1}}{k_{j} k_{j-1}}, \quad i=1,2, \ldots, N \\
& \frac{\partial \rho_{j}}{\partial H}=\frac{1}{\Delta H} \frac{k_{j}-k_{j-1}}{k_{j} k_{j-1}}, \quad j=1,2, \ldots, N
\end{aligned}
$$

where $\rho$ is reactivity, $H$ is height of control rod, $k_{j}$ is effective multiplication factor after movement of control rod at $j$ th step, $k_{j-i}$ is effective multiplication factor before movement of control rod at $j$ th step which is 1 , $N$ is number of steps, and $\Delta H$ is height change of control rod before and after insertions.

The procedure is summarized as:

1. Fuel assemblies are modeled by DRAGON4 and the group constants are calculated.

2. These constants are used to calculate effective multiplication factor using DONJON4.

3. The critical boric acid concentration is calculated in which the effective multiplication factor is 1 . This concentration is obtained by performing steps $1-2$ to assure the reactor criticality through modifying boric acid concentration.

4. The control rod is inserted into core from top to bottom and then the new effective multiplication factor is obtained. The control rod worth is calculated using Eqs. (1) and (2) for current and previous steps.

5. Steps $1-4$ are performed until the control rod is fully inserted to the core.

\section{Results}

In this paper, the rod worth of groups 8,9 , and 10 of the reactor is computed and compared with the FSAR of the plant $[18,19]$. The calculations are performed at hot zero power conditions. In the considered reactor, group 10 of the control rods is the first control group inserted into the core with other groups out of the core. When group 10 is fully inserted the insertion of group 9 starts, and so forth.

All results are compared to those presented in Ref. [10]. Table 2 shows differential and integral control rod worth of group 10 calculated by DRAGON4/ DONGON4 (D4D4) and in the previous work done by WIMS-D4/CITATION (W4C). Figures 4 and 5 illustrate the differential and integral worth of the group.

Table 3 shows the differential and integral rod worth of group 9. Figures 6 and 7 illustrate the differential and integral worth of this group. 
Table 2. Control rod worth of group 10

\begin{tabular}{rccccccrrr}
\hline \multirow{2}{*}{$\begin{array}{c}\text { Position } \\
\text { (\%in) }\end{array}$} & \multicolumn{3}{c}{ Critical boric acid $(\mathrm{g} / \mathrm{kg})$} & \multicolumn{2}{c}{ Differential worth $(\mathrm{pcm} / \mathrm{cm})$} & \multicolumn{3}{c}{ Integral worth $(\%)$} \\
\cline { 2 - 10 } & FSAR & W4C & D4D4 & FSAR & W4C & D4D4 & FSAR & W4C & D4D4 \\
\hline 10 & 7.43 & 7.20 & 7.65 & 0.10 & 0.08 & 0.14 & 0.00 & 0.00 & 0.00 \\
20 & 7.42 & 7.20 & 7.65 & 0.41 & 0.37 & 0.50 & -0.02 & -0.02 & -0.02 \\
30 & 7.41 & 7.19 & 7.64 & 0.85 & 0.75 & 0.98 & -0.05 & -0.05 & -0.05 \\
40 & 7.38 & 7.18 & 7.62 & 1.33 & 1.17 & 1.49 & -0.10 & -0.11 & -0.10 \\
50 & 7.35 & 7.16 & 7.59 & 1.77 & 1.53 & 1.94 & -0.16 & -0.17 & -0.17 \\
60 & 7.31 & 7.13 & 7.56 & 2.04 & 1.75 & 2.25 & -0.23 & -0.25 & -0.25 \\
70 & 7.27 & 7.10 & 7.51 & 1.97 & 1.65 & 2.17 & -0.31 & -0.33 & -0.33 \\
80 & 7.25 & 7.07 & 7.47 & 1.44 & 1.17 & 1.55 & -0.36 & -0.38 & -0.38 \\
90 & 7.23 & 7.05 & 7.44 & 0.72 & 0.56 & 0.76 & -0.38 & -0.40 & -0.40 \\
100 & 7.23 & 7.04 & 7.43 & 0.22 & 0.16 & 0.20 & -0.39 & -0.41 & -0.41 \\
\hline
\end{tabular}

Table 3. Control rods worth of group 9

\begin{tabular}{cccccccccc}
\hline \multirow{2}{*}{$\begin{array}{c}\text { Position } \\
\text { (\%in) }\end{array}$} & \multicolumn{2}{c}{ Critical boric acid $(\mathrm{g} / \mathrm{kg})$} & \multicolumn{2}{c}{ Differential worth $(\mathrm{pcm} / \mathrm{cm})$} & \multicolumn{3}{c}{ Integral worth $(\%)$} \\
\cline { 2 - 10 } & FSAR & W4C & D4D4 & FSAR & W4C & D4D4 & FSAR & W4C & D4D4 \\
\hline 10 & 7.22 & 7.04 & 7.43 & 0.17 & 0.12 & 0.22 & -0.01 & -0.00 & -0.01 \\
20 & 7.21 & 7.03 & 7.43 & 0.72 & 0.68 & 0.85 & -0.03 & -0.03 & -0.04 \\
30 & 7.18 & 7.02 & 7.41 & 1.47 & 1.35 & 1.57 & -0.09 & -0.07 & -0.09 \\
40 & 7.14 & 7.00 & 7.38 & 2.31 & 2.11 & 2.34 & -0.17 & -0.15 & -0.17 \\
50 & 7.08 & 6.97 & 7.33 & 3.21 & 2.95 & 3.23 & -0.28 & -0.25 & -0.28 \\
60 & 7.00 & 6.91 & 7.27 & 4.12 & 3.80 & 4.14 & -0.43 & -0.39 & -0.42 \\
70 & 6.91 & 6.84 & 7.20 & 4.57 & 4.27 & 4.66 & -0.59 & -0.54 & -0.58 \\
80 & 6.84 & 6.77 & 7.11 & 3.73 & 3.51 & 3.83 & -0.73 & -0.66 & -0.71 \\
90 & 6.81 & 6.70 & 7.04 & 1.87 & 1.71 & 1.83 & -0.79 & -0.72 & -0.77 \\
100 & 6.80 & 6.67 & 7.00 & 0.52 & 0.42 & 0.46 & -0.81 & -0.74 & -0.79 \\
\hline
\end{tabular}

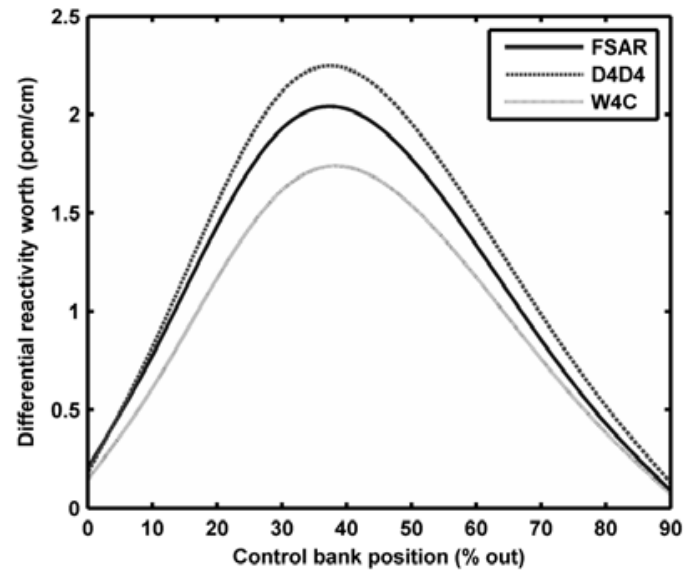

Fig. 4. Differential control rod worth of group 10.

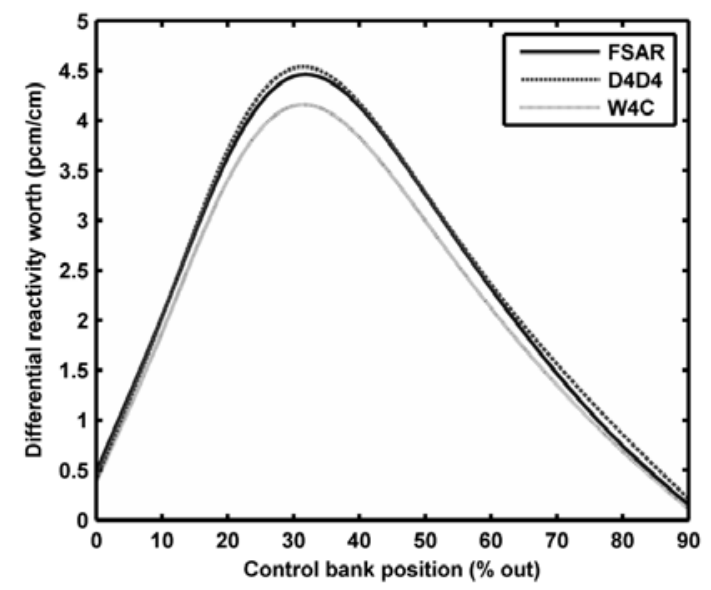

Fig. 6. Differential control rod worth of group 9.

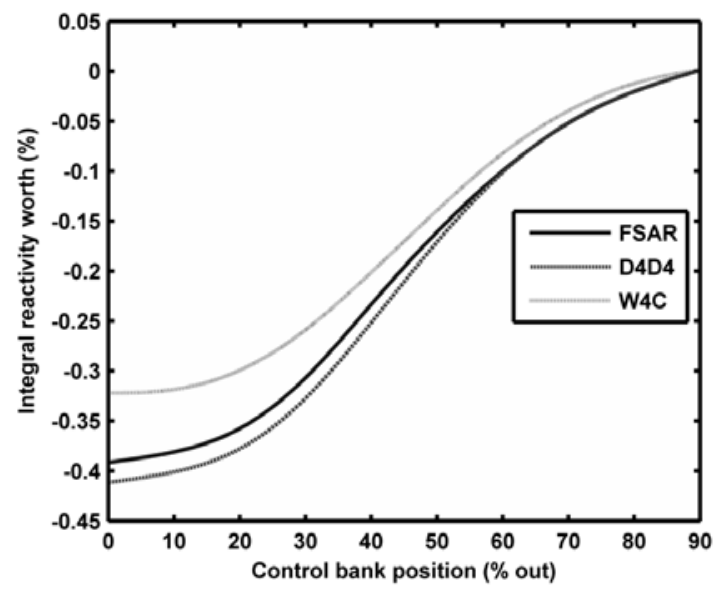

Fig. 5. Integral control rod worth of group 10.

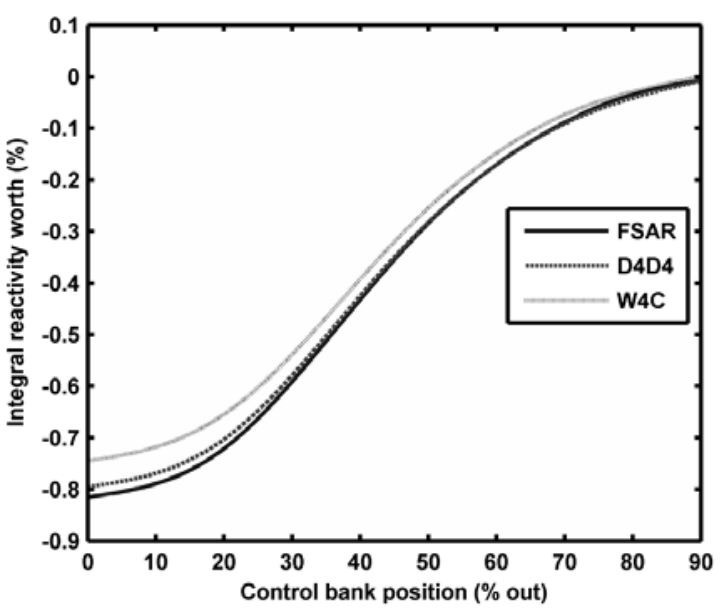

Fig. 7. Integral control rod worth of group 9. 
Table 4. Control rods worth of group 8

\begin{tabular}{cccccccccc}
\hline \multirow{2}{*}{$\begin{array}{c}\text { Position } \\
(\% \text { in })\end{array}$} & \multicolumn{3}{c}{ Critical boric acid $(\mathrm{g} / \mathrm{kg})$} & \multicolumn{3}{c}{ Differential worth $(\mathrm{pcm} / \mathrm{cm})$} & \multicolumn{3}{c}{ Integral worth $(\%)$} \\
\cline { 2 - 10 } & FSAR & W4C & D4D4 & FSAR & W4C & D4D4 & FSAR & W4C & D4D4 \\
\hline 10 & 6.79 & 6.67 & 6.99 & 0.30 & 0.29 & 0.28 & -0.01 & -0.01 & -0.01 \\
20 & 6.77 & 6.66 & 6.98 & 1.14 & 1.21 & 1.13 & -0.05 & -0.05 & -0.06 \\
30 & 6.73 & 6.64 & 6.96 & 2.16 & 2.21 & 2.25 & -0.13 & -0.13 & -0.14 \\
40 & 6.67 & 6.60 & 6.91 & 3.29 & 3.30 & 3.10 & -0.25 & -0.25 & -0.25 \\
50 & 6.58 & 6.54 & 6.85 & 4.72 & 4.78 & 4.51 & -0.41 & -0.41 & -0.42 \\
60 & 6.45 & 6.46 & 6.76 & 6.60 & 6.92 & 6.77 & -0.65 & -0.66 & -0.66 \\
70 & 6.29 & 6.34 & 6.63 & 8.62 & 9.83 & 9.61 & -0.95 & -1.00 & -1.00 \\
80 & 6.13 & 6.16 & 6.44 & 8.55 & 11.50 & 10.17 & -1.26 & -1.41 & -1.36 \\
90 & 6.04 & 5.96 & 6.24 & 4.38 & 6.19 & 5.08 & -1.41 & -1.63 & -1.55 \\
100 & 6.02 & 5.85 & 6.14 & 1.05 & 1.13 & 1.13 & -1.45 & -1.67 & -1.58 \\
\hline
\end{tabular}

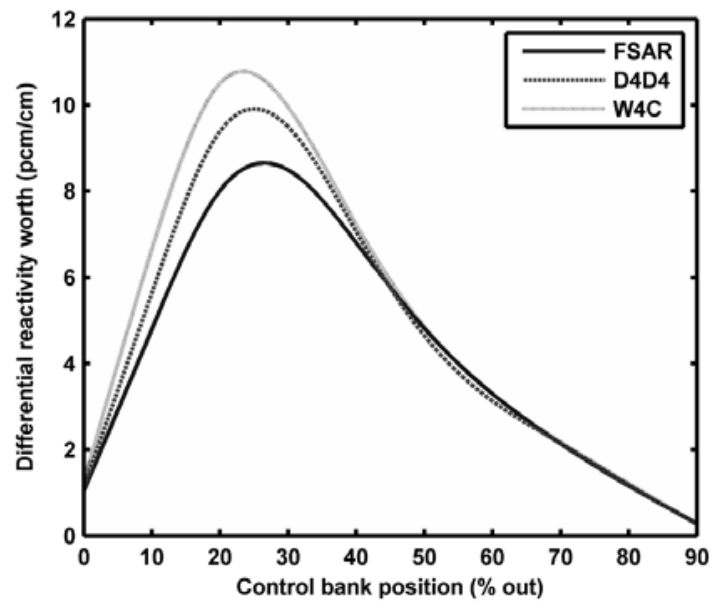

Fig. 8. Differential control rod worth of group 8.

The worth of group 8 is presented in Table 4. The differential and integral worth are shown in Figs. 8 and 9. The results are obtained with control rods of group 9 and 10 in the core. In all of those tables, the respective boric acid concentrations are obtained by iterating boron concentration to criticality and then reactivity change is calculated by Eqs. (1) and (2).

The differential worth overestimate the reference FSAR values for all calculated control rod groups, but they are closer to them than the WIMS-D4/CITATION values. The integral control rod worth overestimate the FSAR values for groups 10 and 8 and slightly underestimate for group 9 being always closer to FSAR values than the W4C ones.

A systematic comparison of results based on DRAGON4 and DONJON4 approach to the reference values of FSAR shows their superiority over those obtained from WIMS-D4/CITATION caused by a more adequate model in cell calculations.

\section{Conclusion}

In the present work, a package based on computer codes DRAGON4 and DONJON4 has been applied for calculation of the reactivity worth of control rods of VVER-1000 reactor. The differential and integral worth of the rod are obtained by an auxiliary computer program that couples these codes and calculates the critical boric acid concentration. The results of this study are compared with the FSAR of the plant and

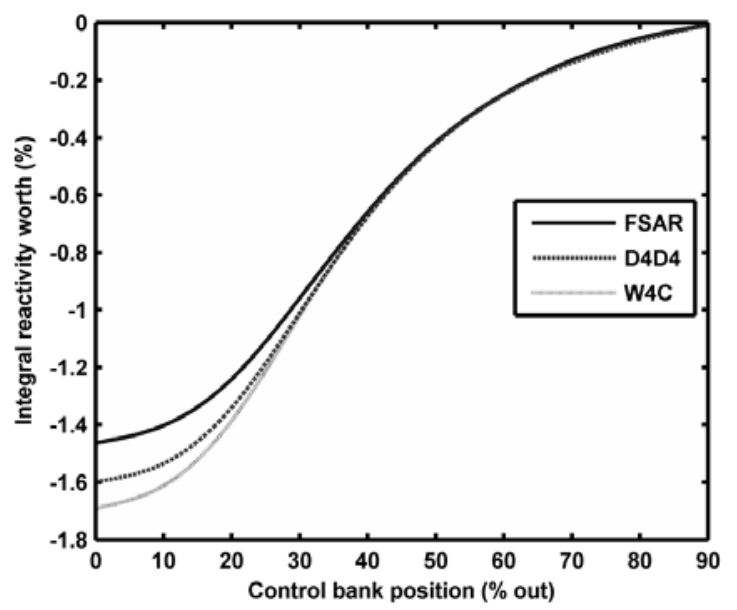

Fig. 9. Integral control rod worth of group 8.

the previous study done by WIMS-D4/CITATION. The accuracy of obtained results from proposed method is validated based on these data. However, they could be validated by experimental measurement or stochastic calculations. The method estimates the worth more accurately than WIMS-D4/CITATION and shows its capability to effectively and accurately calculate the reactor physics parameters.

\section{References}

1. Lee, E. K., Shin, H. C., Bae, S. M., \& Lee, Y. K. (2005). New dynamic method to measure rod worths in zero power physics test at PWR startup. Ann. Nucl. Energy, 32, 1457-1475.

2. Shimazu, Y., Okazaki, K., \& Tsuji, M. (2006). Feasibility study for evaluation of control rod worth in pressurized water reactors using neutron count rate during a control rod drop testing. Nucl. Sci. Technol., 43, 919-923.

3. Kalcheva, S., \& Koonen, E. (2009). Improved Monte CarloPerturbation method for estimation of control rod worths in a research reactor. Ann. Nucl. Energy, 36, 344-349.

4. Varvayanni, M., Savva, P., \& Catsaros, N. (2009). Control rod worth calculations using deterministic and stochastic methods. Ann. Nucl. Energy, 36, 1718-1725.

5. Petit, O., Hugot, F. -X., Lee, Y. -K., Jouanne, C., \& Mazzolo, A. (2008). TRIPOLI-4 Version 4 User Guide. (CEA-R-6169). Code Available from OECD/NEA Data Bank.

6. Greene, N. M., Petrie, L. M., \& Westfall, R. M. (2000). NITAWL-II: scale system module for performing resonance shielding and working library production. (NUREG/CR- 
-0200). Revision 6, V. 2, Section F2. (ORNL/NUREG/ CSD-2/V2/R6).

7. Greene, N. M., \& Petrie, L. M. (2000). XSDRNPM: $a$ one-dimensional discrete-ordinates code for transport analysis. Oak Ridge National Laboratory. (NUREG/ CR-0200). Revision 6, V. 2, Section F3. (ORNL/NUREG/ CSD-2/V2/R6).

8. Fowler, T. B., Vondy, D. R., \& Guningham, G. W. (1971). Nuclear reactor core analysis code: CITATION. Oak Ridge National Laboratory. (ORNL-TM-2496). Rev. 2.

9. Savva, P., Varvayanni, M., \& Catsaros, N. (2011). Dependence of control rod worth on fuel burnup. Nucl. Eng. Des., 241, 492-497.

10. Fadaei, A. H., \& Setayeshi, S. (2009). Control rod worth calculation for VVER-1000 nuclear reactor using WIMS and CITATION codes. Prog. Nucl. Energy, 51, 184-191.

11. Winfrith. (1982). LWR-WIMS, a computer code for light water reactor calculations. AEE, UK. AEEW-R 1498.

12. D'Auria, F., Fischer, K., Mavko, B., \& Sartmandjiev, A. (2001). Validation of accident and safety analysis methodology. Vienna: IAEA. (CRP/J.020.03).
13. Internationa Atomic Energy Agency. (2008). Best estimate safety analysis for nuclear power plants: uncertainty evaluation. Vienna: IAEA. (Safety Series Report No. 52).

14. Marleau, G., Hébert, A., \& Roy, R. (2011). A user guide for DRAGON Version 4. Institut de génie nucléaire, Département de génie mécanique, École Polytechnique de Montréal. (Report IGE-294).

15. Popov, A. V., \& Olekhnovitch, A. (2012). Adapting the feed-back model to dynamic core heterogeneity. Ann. Nucl. Energy, 48, 134-137.

16. Popov, A. V., Olekhnovitch, A., \& Fassi Fehri, M. (2012). LBLOCA in CANDU-NG cooled by light water. Ann. Nucl. Energy, 45, 161-165.

17. Sekki, D., Hébert, A., \& Chambon, R. (2011). A user guide for DONJON Version 4. Institut de génie nucléaire, Département de génie mécanique, École Polytechnique de Montréal. (Report IGE-300).

18. AEOI. (2006). Album of neutron and physical characteristics of the initial fuel inventory. Refers to Organization of operation on BNPP-1.

19. AEOI. (2007). Final safety analysis report, Chapter 4, REACTOR. Atomic Energy Organization of Iran. 